\title{
Grain Growth after Intercritical Rolling
}

\author{
R. Petrov, L. Kestens, K. Verbeken and Y. Houbaert \\ Department of Metallurgy and Materials Science, Ghent University, \\ Technologiepark 903, 9052 Ghent, Belgium
}

Keywords: Grain size, Intercritical rolling, Steel, Microstructure, Texture

\begin{abstract}
The distribution of the characteristic texture components between the ferrite grains of different size classes has been studied in a steel with $0.082 \% \mathrm{C}, 1.54 \% \mathrm{Mn}, 0.35 \% \mathrm{Si}, 0.055 \% \mathrm{Nb}$ and $0.078 \% \mathrm{~V}$ after different rolling schedules with a final rolling temperature above or below $\mathrm{Ar}_{3}$. Microstructures and textures were characterized by means of optical microscopy and orientation microscopy. A strong grain refining effect together with a bimodal grain size distribution was observed in the steel both after final rolling in the intercritical region or in the austenite region, close to the $\mathrm{Ar}_{3}{ }^{\mathrm{d}}$ temperature. The differences in grain size were interpreted on the basis of three potentially acting mechanisms: (i) transformation-induced recrystallization, (ii) increased mobility of specific grain boundaries and (iii) fast nucleation of ferrite grains on specific sites of the parent austenite microstructure. The experimental data clearly favoured the third of these assumptions as the responsible mechanism for the observed bimodal grain size distributions.
\end{abstract}

\section{Introduction}

In some cases the rolling of thin gauge strips can be finished in the intercritical $\gamma+\alpha$ region. This may produce an undesirable coarse-grained microstructure $[1,2,3,4]$ and a texture gradient from the surface to the centre of the strips [2] that can give rise to bad mechanical properties. Vanderschueren et al. [2] observed this phenomenon in plain carbon steels, which were finished in the twophase region. They explained this behaviour by the existence of austenite grains that transformed to virtually dislocation free ferrite grains, which act as nuclei for the subsequent recrystallization of the strained ferrite. The authors called this phenomenon transformation induced recrystallization and mentioned that it did not appear when Ti based precipitates interact with the recrystallization process. Bodin et al $[3,4]$ gave the same explanation for the observed ferritic grain growth which gave rise to a bimodal grain size distribution after intercritical rolling of C-Mn and low carbon steels. In both cases, there were no direct observations of the local texture or specific crystallographic orientations of large and small grains separately.

On the other hand, a strong grain refining effect was observed by Bleck et al [5] after uniaxial compression of a C-Mn-Nb steel in the intercritical region followed by controlled cooling and by Petrov et al [6] after industrial rolling of $\mathrm{C}-\mathrm{Mn}-\mathrm{Nb}$ steel finished close to the $\mathrm{Ar}_{3}$ temperature.

Although rolling in the two-phase $\alpha+\gamma$ region is of great practical importance for structure and texture formation of thin gauge hot rolled strips, the above examples show that there are contradictive data with regard to grain size and grain size distribution. A satisfactory explanation for the occurrence of a bimodal grain size distribution after intercritical rolling does not exist and there is a deficiency of experimental data on this subject in the scientific literature. The goal of the present work is to obtain a better understanding of the acting mechanism for the formation of the microstructure during intercritical rolling of a carbon - manganese steel, in order to create possibilities for further improvement of their properties (strength, toughness and deep drawability). 


\section{Experimental}

Rough rolled blocks of which the chemical composition is listed in Table 1, and with dimensions $140 \times 100 \times 35 \mathrm{~mm}^{3}$ were hot rolled in a laboratory rolling mill to a thickness that varied from 4 to $2.75 \mathrm{~mm}$ according to the rolling schedules shown Fig.1. Four rolling schedules were designed on the base of the experimentally deduced CCT

Table 1 Chemical composition of the steel

Chemical composition [mass.\%]

\begin{tabular}{llllllllll}
$\mathrm{C}$ & $\mathrm{Mn}$ & $\mathrm{P}$ & $\mathrm{S}$ & $\mathrm{Si}$ & $\mathrm{Al}$ & $\mathrm{Nb}$ & $\mathrm{V}$ & $\mathrm{N}$ \\
\hline
\end{tabular}

0.0821 .540 .010 .0060 .360 .0330 .0550 .0780 .005 diagram of the steel, which is reported elsewhere [7]. The first rolling schedule (named $1 \mathrm{CS}$ ) consists of 3 rolling passes above the austenitic non recrystallization temperature $\left(\mathrm{T}_{\mathrm{nr}}\right)$ and 3 rolling passes below the $\mathrm{Ar}_{3}$ temperature, i.e. there is no rolling in the region between $\mathrm{T}_{\mathrm{nr}}$ and $\mathrm{Ar}_{3}$, and thus the austenite will be completely recrystallized before the start of the $\gamma / \alpha$ transformation. The rolling schedule indicated as 2CS is a more classical one in which the final rolling temperature (FRT) is above the $\gamma / \alpha$ transformation temperature of strained austenite $\left(\mathrm{Ar}_{3}{ }^{\mathrm{d}}\right)$. These two rolling schedules were followed by a coiling simulation (CS) at $600^{\circ} \mathrm{C}$ in a computer-controlled furnace. It should be mentioned that the transformation temperature of the strained austenite $\mathrm{Ar}_{3}{ }^{\mathrm{d}}$ is higher than the $\gamma / \alpha$ transformation temperature $\mathrm{Ar}_{3}$ of non-strained austenite because of the changes in the substructure (i.e. the energy) of the strained austenite [7].
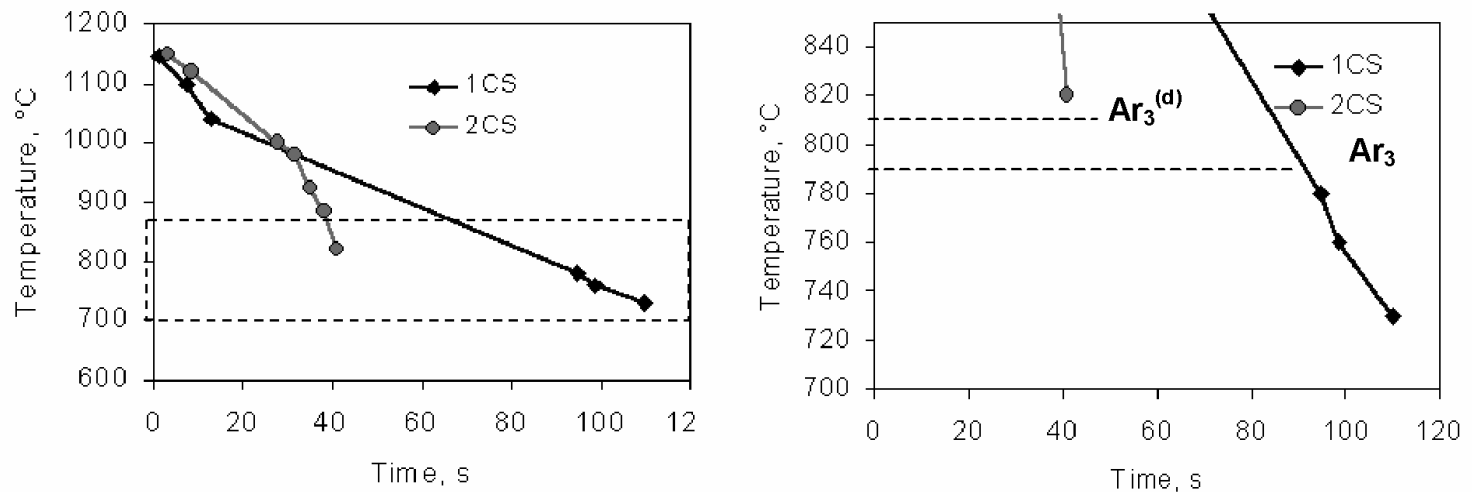

Fig.1: (a) A record of cooling during rolling schedules 1CS and 2CS; (b) A detailed view displaying the exact value of the rolling temperatures with respect to the $\mathrm{Ar}_{3}{ }^{\mathrm{d}}$ and $\mathrm{Ar}_{3}$ temperature.

The same rolling schedules were also performed, followed by a water quench after the last rolling pass at different temperatures between the last rolling pass and the coiling temperature $\left(600^{\circ} \mathrm{C}\right)$. This allowed to study the ferrite grain size evolution in the intercritical region. The rolling temperature together with the rolling passes for schedules 1CS and 2CS were recorded vs. time and plotted as shown in Fig.1.

The samples for metallographic observations were cut from the middle of the rolled sheet and the microstructure was studied in the plane perpendicular to the transverse direction after an appropriate sample preparation. This included mechanical grinding and polishing up to $1 \mu \mathrm{m}$ diamond paste, followed by $2 \%$ nital etching for observation in the optical microscope or the SEM. An additional electrolytic polishing stage after the mechanical one followed by $2 \%$ nital etching is required for the OIM samples. The OIM attachment was installed on a Philips XL30 ESEM with an $\mathrm{LaB}_{6}$ filament and the electron backscattering diffraction (EBSD) patterns were acquired and analyzed by means of the commercial TSL ${ }^{\circledR}$ OIM software [8]. 


\section{Results and discussion}

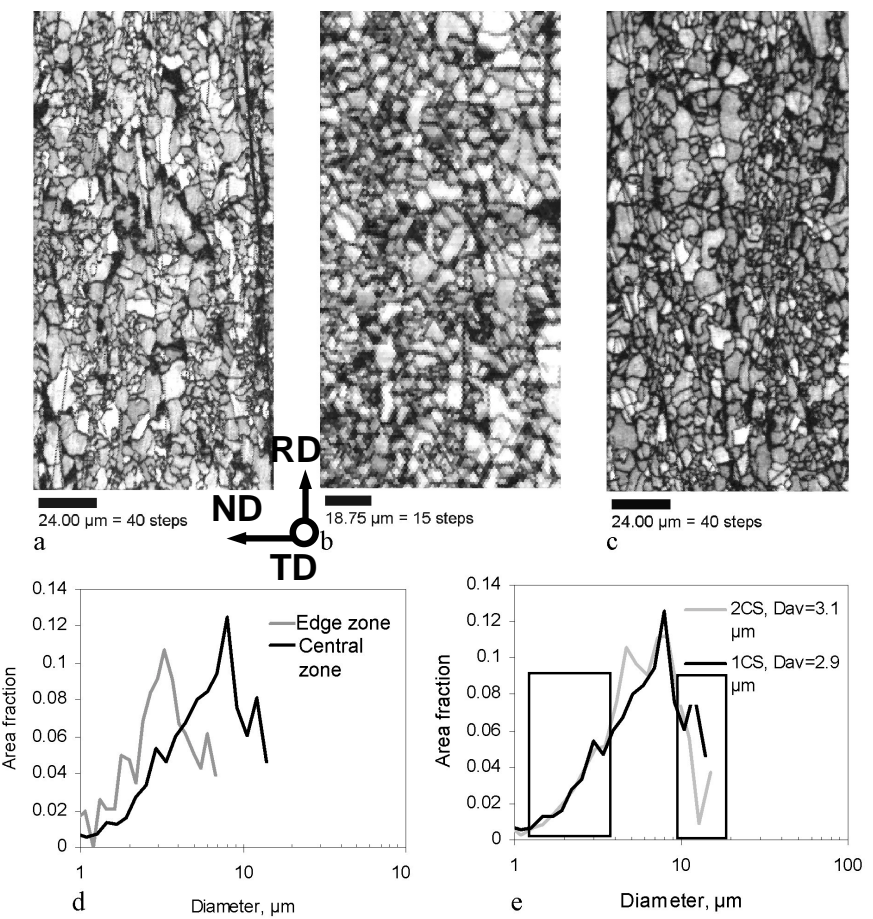

Fig.2. (a) and (c) Middle thickness microstructure of strips 1CS and 2CS; (b) Surface microstructure of strip 1CS. (d) Grain size distribution in the surface and center of the strips 1CS and (e) in the center of the strips $1 \mathrm{CS}$ and $2 \mathrm{CS}$.
Three different possibilities for grain growth were explored in order to explain the preferential growth of the large grains: (i) transformation induced recrystallization; (ii) selective growth of specific orientations and (iii) growth advantage based on the fact that first nuclei grow first. The orientation data were partitioned between the large and small grains. The textures of the large and the small grains were compared with the theoretically predicted ferrite transformation textures produced from strained and non-strained parent austenite. If transformation induced recrystallization is the acting mechanism for preferential growth, the large grains must display a transformation texture originating from strained austenite, whereas the texture of the small grains should be typical for warm rolled or recrystallized ferrite grains. Fig. 2 displays the Image Quality (IQ) maps of strips 1CS and 2CS that were finished below and above the $\mathrm{Ar}_{3}$ temperature respectively. There were no significant differences with regard to microstructure and grain size in

the midsections of these strips. In both strips the following features were observed $(i)$ a strong grain refining effect and (ii) a bimodal grain size distribution. The grains larger than $10 \mu \mathrm{m}$ and smaller than $3 \mu \mathrm{m}$ were selected as representatives for the large and the small grains (cf. Fig.2c) and their textures are displayed in Fig.3. Fig 4 displays the ideal BCC product orientations in the $\varphi_{2}=45^{\circ} \mathrm{sec}$ tion together with the FCC parent orientations from which they originate according to the Kurdjumov-Sachs relations. Fig. 4 should be used as a key to interpret the experimental data presented in Figs. 3a-d.

The texture of the ferrite grains smaller than $3 \mu \mathrm{m}$ (cf.Fig.3a and c) is the transformation texture that could be obtained when a strained parent austenite phase (mainly with Brass $\{110\}\langle 112\rangle$ and Copper $\{112\}\langle 111\rangle$ orientations) transforms to ferrite according to K-S transformation law. The product ferrite orientations are usually situated on the so-called "transformation" or $\beta$-fibre (dashed lines in Fig.3.a-c). As it was expected the grains
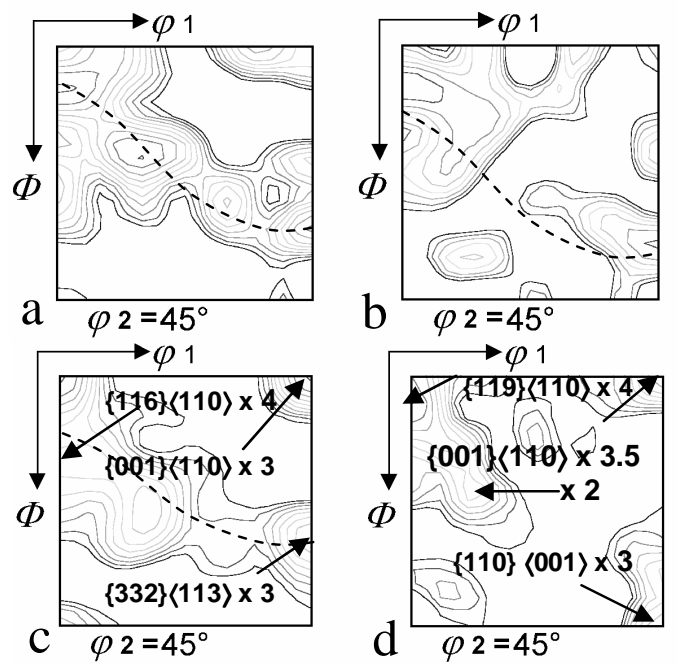

Fig. 3 A $\varphi_{2}=45^{\circ}$ sections of ferrite ODFs of small $(\mathrm{a}, \mathrm{c})$ and large $(\mathrm{b}, \mathrm{d})$ grains in strips 2CS (a,b) finished above $\mathrm{Ar}_{3}{ }^{\mathrm{d}}$ and $1 \mathrm{CS}$ (c, d) finished below $\mathrm{Ar}_{3}$ temperatures. 
larger than $10 \mu \mathrm{m}$ in the strip 2CS, which was finished above the $\mathrm{Ar}_{3}{ }^{\mathrm{d}}$ temperature also display the

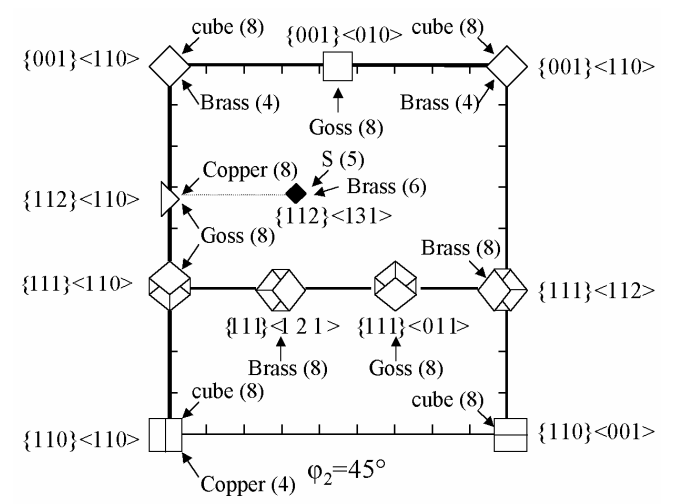

Fig.4 Selected BCC product orientations in the $\varphi_{2}=45^{\circ}$ section shown together with FCC parent orientations from which they originate according to the K-S relations [9] same type of transformation texture (cf.Fig.3b) as the small grains (i.e. ferrite transformation texture originating from strained austenite parent phase) because the austenite was deformed prior to the $\gamma / \alpha$ transformation.

Fig.3d displays the texture of the grains larger than 10 $\mu \mathrm{m}$ in the strip 1CS (finished below the $\mathrm{Ar}_{3}$ temperature). The rotated cube $\{001\}\langle 110\rangle$ texture component in the ODF can be attributed to the transformation product of strained austenite with Brass $\{110\}\langle 112\rangle$ orientation or to the transformation product of the recrystallized austenite parent phase, while the observed strong rotated Goss $\{110\}\langle 001\rangle$ texture component can only be obtained after transformation of the recrystallized austenite parent phase with cube $\{001\}\langle 100\rangle$ orientation. If the transformation induced recrystallization mechanism acts, the large grains should display the transformation texture originating from strained austenite, because they are the

ones that according to the transformation induced recrystallization hypothesis first transform to recrystallized ferrite and act as nuclei for ferrite recrystallization afterwards. Hence, the transformation induced recrystallization hypothesis cannot explain the bimodal grain size distribution in the present experiment. Another possible mechanism for preferential grain growth could be associated with the possible special misorientation relationships between the growing grains and their neighbours that supports fast growth of specific orientations, which refers to a classical selective growth theory. In order to explore this assumption, 263 local misorientations between the large grains and their neighbours were measured in the sample 2CS, finished above the $\mathrm{Ar}_{3}{ }^{\mathrm{d}}$ temperature, and 260 local misorientations were evaluated in the sample 1CS that was finished below the $\mathrm{Ar}_{3}$ temperature. The schedule of this measurement is illustrated in Fig.5. Only $12 \%$ of the measured grain boundaries in the 2CS sample and $14 \%$ of the measured grain boundaries in the 1CS sample were closely related to a type of Coincidence Site Lattice boundary, which are often associated with an increased grain boundary mobility. No specific type of CSL prevailed though and the reported fractions are

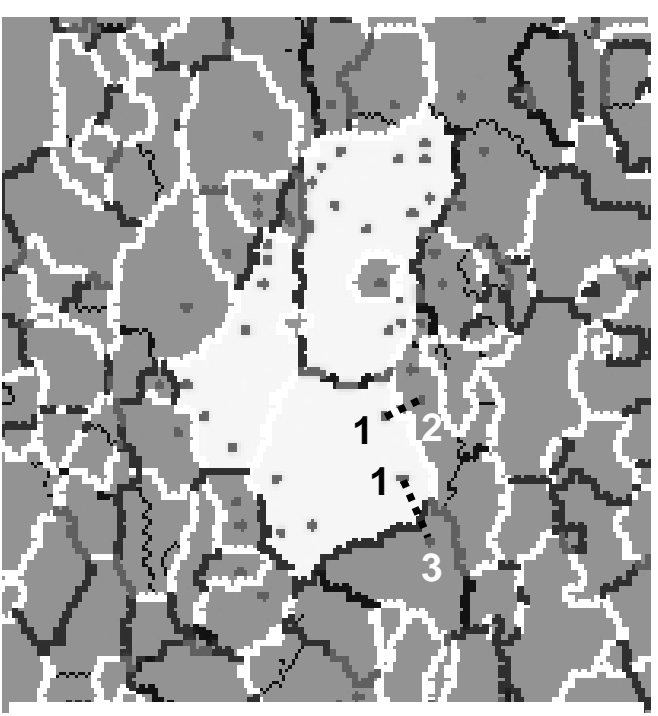

Fig.5. OIM map, which displays rotation angle grain boundaries with misorientation of $5-15^{\circ} ; 15-20^{\circ} ; 20-$ $40^{\circ}$ and $40-65^{\circ}$ (From light to dark). The local misorientation between the large grains (grain 1) and the neighboring grains (2, 3 etc.) is measured between the marked not significantly different from the ones observed in a random misorientation distribution. According to some authors middle orientation boundaries (with misorientation angles between $20^{\circ}$ and $30^{\circ}$ ), rather than CSL boundaries are responsible for selective growth. The fractions of various misorientation classes (large, middle and small) are shown in Fig. 6 for the samples 1CS and 2CS. For each sample a comparison is made between the misorientation profile observed for the entire sample and the profile obtained from local misorientation data between large and small ferrite grains. For all misorientation classes the difference between the 


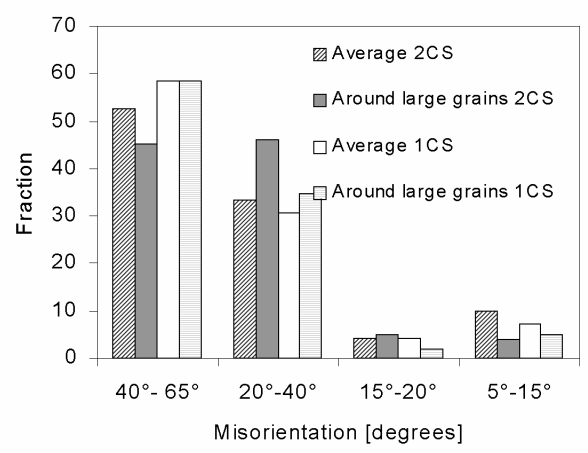

Fig.6 Fraction of the grain boundaries with different misorientation for the overall scan and in the neighborhood of the large grains global and local misorientation profiles could be ignored, except for the sample $2 \mathrm{CS}$, which displayed a slight dominance of middle orientation boundaries around the large (growing) grains. It remains to be verified, though, on sound statistical grounds whether or not this is a significant result.

The third assumption, surmising that the first transformation nuclei grow first (i.e. the oriented nucleation hypothesis) was explored by means of a detailed microstructural observation of the specially prepared samples, finish hot rolled at $820^{\circ} \mathrm{C}$, which is above the $\mathrm{Ar}_{3}{ }^{\mathrm{d}}$ temperature (but below $\mathrm{T}_{\mathrm{nr}}$ ) and water quenched from different temperatures in the intercritical range. In this way the microstructural changes were traced in the temperature range between the final rolling pass and the coiling tem-

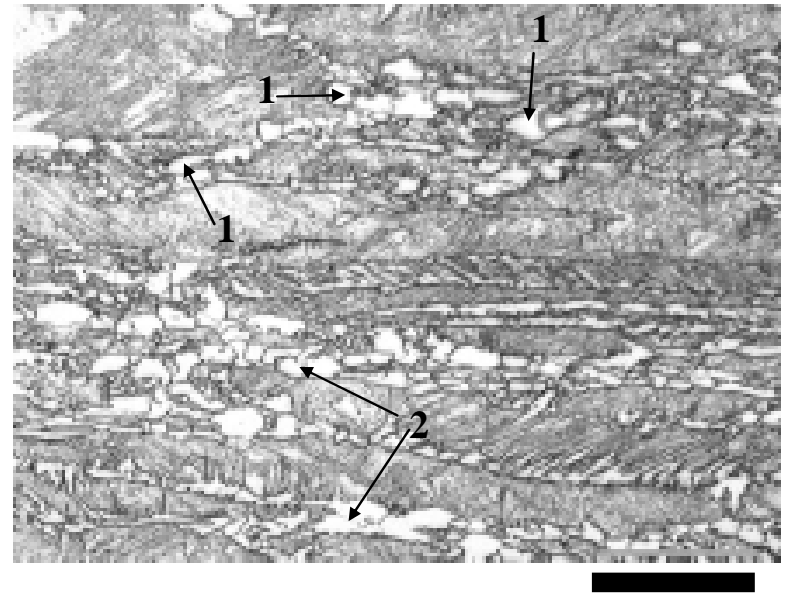

a

$25 \mu \mathrm{m}$

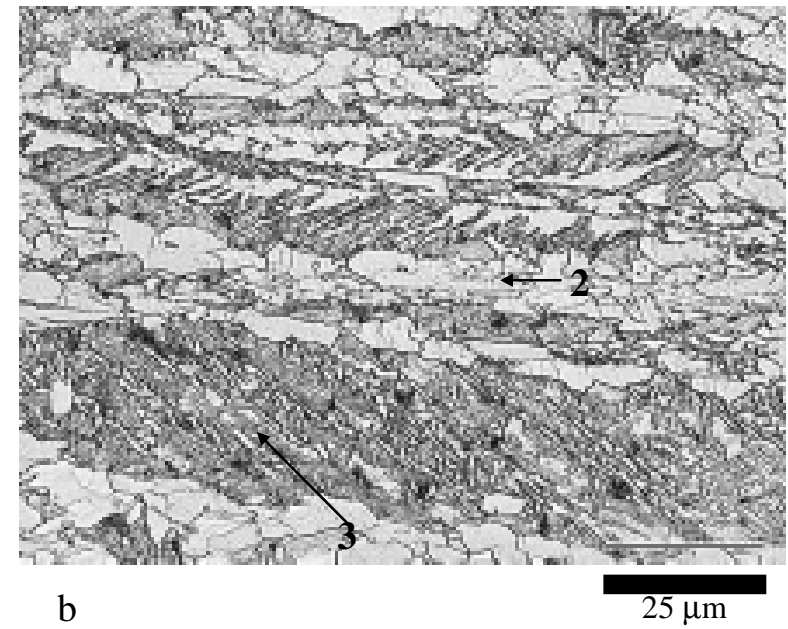

$25 \mu \mathrm{m}$

Fig. 7 (a) Microstructure of strip finished at $820^{\circ} \mathrm{C}$ and next water quenched from $780^{\circ} \mathrm{C}(\sim 30 \%$ ferrite phase) (b) water quenched from $685^{\circ} \mathrm{C}(\sim 50 \%$ ferrite phase $)$. 1- nuclei on the triple junction points; 2-nuclei on the grain boundaries; 3- nuclei on the shear bands. At $685^{\circ} \mathrm{C}$ large ferritic grains already exist in the microstructure without intercritical rolling.

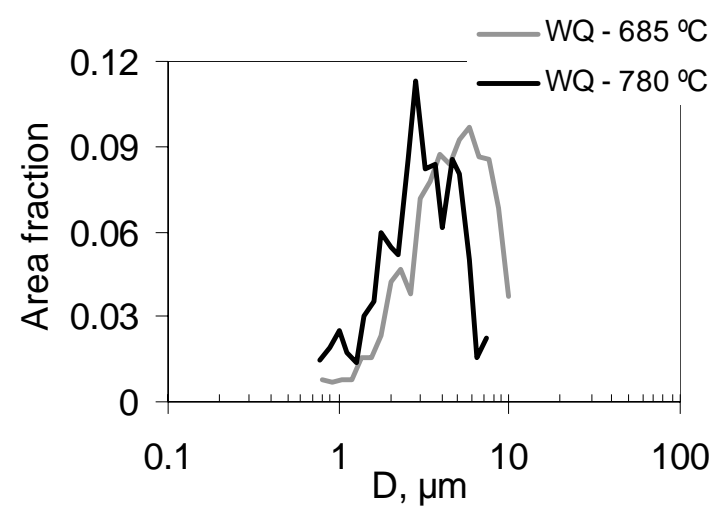

Fig. 8 Grain size distribution in terms of area fraction observed after quenching at 685 and $780^{\circ} \mathrm{C}$, respectively. perature. Fig. 7 displays the microstructure of strips, which were hot rolled under the conditions of rolling schedule $2 \mathrm{CS}$ but instead of being slowly cooled in a coiling simulation they were air cooled to different intercritical temperatures and next water quenched. The first ferrite nuclei appear mainly on the former austenite grain boundaries (Fig.7a, points 2 ), but the largest nuclei were observed on the triple junction points (cf. points 1 in Fig. 7a). These two groups of nuclei seem to have a preferential growth after the further decrease of the temperature. At lower temperatures small amounts of new nuclei were observed inside the austenite grains in the shear bands or twins (Fig.7b, point 3) as it was observed also by Khlestov et al [11]. With decreasing 
quenching temperature the ferrite growth is clearly observed in the microstructure as it is shown in Fig. 7a and b. The black line in Fig. 8 shows the grain size distribution of the ferritic grains at temperatures close to $\mathrm{Ar}_{3}$ and it is easy to be seen that the area fraction of the large grains is relatively low in comparison to the one corresponding to the small grains. The decrease of the quench temperature, however, leads to an increase of the fraction of large grains and the appearance of the bimodal shape of the curve (cf. Fig.8). Hence, these data strongly suggest that the growth advantage of the first ferritic nuclei has contributed to the development of a bimodal grain size distribution as observed in the present experiment.

\section{Conclusions}

A strong grain refining effect and a bimodal grain size distribution is observed both after final rolling above and below the $\mathrm{Ar}_{3}$ temperature. The observed bimodal grain size distribution after intercritical rolling of the studied $\mathrm{Nb}-\mathrm{V}$ alloyed carbon-manganese steel cannot be explained by the transformation induced recrystallization hypothesis, whereas a more detailed statistical analysis is required to clarify the role of selective growth. It could be established, however, that preferential nucleation of ferrite grains in the vicinity of austenite grain boundaries and triple junctions has lead to a significant size advantage to these grains in the ensuing growth stage, which has largely contributed to the formation of a bimodal grain size distribution.

Acknowledgements: The authors gratefully acknowledge the financial support of this study granted by the Netherlands Institute for Materials Research (NIMR) and CORUS-R\&D Group is acknowledged for providing the material.

\section{References}

[1] G. Kim and O.Kwon: Proc. Thermec 88, ed. by Tamura I., ISIJ, Tokyo, (1988), 668-675.

[2] D. Vanderschueren, L. Kestens, et al: Mater. Sci and Technology, Vol. 6, (1990), 1247-1259.

[3] A. Bodin, J. Sietsma and S. van der Zwaag: Mater. Trans. A Vol.33,No 6, (2002), 1589 - 1603.

[4] A. Bodin, J. Sietsma and S. van der Zwaag: Mater. Charact., Vol. 47, (2002), 1589 - 1603.

[5] W. Bleck, C. Herzig and U. Lorenz: Steel Research, Vol. 72, No 10, (2001), 406-410.

[6] R. Petrov, L. Kestens,: ISJI International, Vol.43, No 3 (2003), 378-385.

[7] R.Petrov, L. Kestens, and Y. Houbaert: Proc. of COM2003, Vancouver, CA, (2003), 315-329.

[8] TSL® OIM Analises for Windows: Version 3.03, (2000).

[9] M.P. Butron Guilen, J.J. Jonas and R.K. Ray: Acta Metall. Mater. Vol.42, No 11, (1994), 36153627.

[10] K. Verbeken, L. Kestens, J.J. Jonas, Scripta Mat. (2003), 1458-1462.

[11] V.M. Khlestov, E.V. Konopleva and H.J. McQueen: Canadian Metallurgical Quarterly, Vol.40, No 2, (2001), 221-234.

http://www.ttp.net/download

\section{爬包 Trans Tech Publications Ltd}

Brandrain 6

CH-8707 Uetikon-Zuerich
Fax: $\quad+41-19221033$

e-mail: $\quad$ ttp@ttp.net 
